\title{
Superplastic deformation of fine-grained AE42 and LAE442 magnesium alloys
}

\author{
P. Minárik ${ }^{1, \dagger}$, T. Vávra ${ }^{1}$, J. Stráský1 ${ }^{1}$ B. Hadzima², R. Král ${ }^{1}$ \\ †peter.minarik@mff.cuni.cz \\ ${ }^{1}$ Department of Physics of Materials, Faculty of Mathematics and Physics, Charles University, \\ Ke Karlovu 5, 12116 Praha, Czech Republic \\ ${ }^{2}$ University of Žilina, Research centre, Univerzitná 8215/1, Žilina, Slovak Republic
}

In this paper, the possible superplastic behaviour of fine-grained magnesium alloys AE42 and LAE442 alloys was investigated and the first results of this research are shown. Two deformation temperatures and two strain rates were selected upon the initial measurement of thermal stability and dependence of $m$-parameter on strain rate and temperature. Evolution of $m$-parameter during the tensile tests was measured by means of periodical switching of the strain rate. The LAE442 alloy showed significantly higher elongations at the same deformation conditions as comparing to the AE42 alloy. The highest values of $m$-parameter in the last stage of deformation were measured at the temperature of $240{ }^{\circ} \mathrm{C}$ and strain rate of $10^{-4} \mathrm{~s}^{-1}$, regardless much higher grain growth comparing to deformation at $180^{\circ} \mathrm{C}$. Consequently, deformation of about $1.5(350 \%)$ and $1.3(270 \%)$ was measured for LAE442 and AE42 alloys, respectively. Higher values of $m$-parameter during the deformation and consequently higher elongation observed in LAE442 alloy were attributed to a combination of higher thermal stability and the positive effect of lithium on the activation of non-basal slip systems and diffusion.

Keywords: superplasticity, magnesium, thermal stability, ultrafine-grained, equal channel angular pressing.

\section{Introduction}

The LAE442 magnesium alloy containing lithium, aluminium and rare earth elements mischmetal is one of the most investigated alloys with regard to the potential use in medicine. Adequate biocompatibility, biodegradability and degradation rate have been proven in numerous works in the as-cast, as-extruded and also fine-grained conditions (see, for example, $[1,2]$ and literature cited herein). Design of potential medical implants can have a complicated shape and the fine-grained structure of this material could provide a possibility to exploit superplastic deformation during the fabrication of these implants.

Superplasticity refers to the ability of a crystalline material to sustain large deformation, usually above $400 \%$ [3]. The other definition is through the strain rate parameter $m$, which needs to be higher than 0.3 [4] or 0.5 [3], depending on the literature. Usually, both of these conditions are met together. Superplastic behaviour was found in the whole range of materials including alloys, intermetallic compounds and ceramics [5].

Until now, a high number of magnesium alloys have been investigated for superplastic behaviour. One of the most investigated alloy systems is $\mathrm{Mg}-\mathrm{Al}-\mathrm{Zn}$, the typical representative of which is the AZ31 alloy, which exhibited very high strains at temperatures below $350{ }^{\circ} \mathrm{C}$ and strain rates lower than $10^{-3} \mathrm{~s}^{-1}$. Lately, much higher processing rates were found in $\mathrm{Mg}$-RE alloys, which are therefore commercially more attractive [6]. Utilization of much higher strain rates was enabled particularly by the higher stability of the (ultra)fine-grained microstructure due to $\mathrm{Mg}$ - $\mathrm{RE}$ precipitates, and consequently, much higher processing temperature could be used [6-8].

In this research, the LAE442 alloy and its lithium-free counterpart were investigated for possible superplastic behaviour. As mentioned, the LAE442 alloy is today of high interest because of its potential use in medicine. The AE42 alloy is a creep resistant alloy used in hightemperature applications [9]. This alloy was particularly chosen in order to investigate the effect of lithium on the high-temperature plasticity and possible superplasticity of the LAE442 alloy. Lithium-containing magnesium alloys have been already investigated in this regard previously $[10-13]$. Low temperature and even room temperature superplasticity were achieved particularly in $\alpha+\beta \mathrm{Mg}-\mathrm{Li}$ alloys. The superplastic behaviour was attributed particularly to the presence of Li segregation and Li-rich interphases in the grain boundaries, which significantly increase the grain boundary diffusion $[11,13]$. Nevertheless, accommodation of grain boundary sliding by slip is facilitated in these alloys, due to increased activity of non-basal slip systems in the $\alpha$-phase and presence of BCC lattice in the $\beta$-phase. In this report, the first results of this research are summarized.

\section{Experimental material and methodology}

The commercial alloy AE42 (Mg-4\% Al-2\% RE) and noncommercial one LAE442 (Mg-4\% Li-4\% Al-2\% RE) were investigated in the fine-grained condition achieved by equal channel angular pressing (ECAP). A detailed description 
of the composition and processing parameters is given elsewhere [14].

Similar fine-grained microstructures were achieved in both alloys, consisting of grains having an average size of $1.5 \mu \mathrm{m}$ separated by a high fraction of high angle grain boundaries, see Fig. 1. The AE42 alloy contained a homogenous distribution of thermally stable $\mathrm{Al}_{11} \mathrm{RE}_{3}$ particles [15]. On the other hand, lithium addition to the LAE442 alloy resulted in the formation of a random distribution of thermally unstable nanocrystalline $\mathrm{Al}$ particles, besides the thermally stable ones [16].

The microstructural changes were investigated by means of electron-backscattered diffraction (EBSD). The samples were prepared via mechanical grinding and polishing with decreasing particle size to $0.25 \mu \mathrm{m}$ followed by ion-polishing using Leica EM RES102. The evolution of average grain size was investigated by scanning electron microscope (SEM) FEI Quanta $^{\mathrm{Tm}}$ FX200 equipped with EDAX EBSD camera. The size of the EBSD map was at least $100 \times 100 \mu \mathrm{m}$ with a step size of $0.1 \mu \mathrm{m}$.

Tensile deformation tests were performed using the INSTRON 5882 deformation machine at the selected temperatures and strain rates. Dog-bone-shaped samples were cut from the billet with the deformation direction parallel to the ECAP direction. The samples were $1 \mathrm{~mm}$ thick with the active part $14 \mathrm{~mm}$ long and $4 \mathrm{~mm}$ wide. All tensile tests were performed with the constant true strain rate. At least two tensile tests were performed for each condition.

\section{Results and discussion}

\subsection{Thermal stability}

At first, the thermal stability of the processed fine-grained microstructure was investigated in both alloys by means of isochronal annealing at the temperatures of $180{ }^{\circ} \mathrm{C}$, $200{ }^{\circ} \mathrm{C}, 220^{\circ} \mathrm{C}, 240{ }^{\circ} \mathrm{C}$ and $260^{\circ} \mathrm{C}$. The samples were put in the preheated furnace and after 20 minutes of annealing were water-quenched. Effect of annealing on the grain size was investigated by EBSD and the results are shown in Fig. 2. Note, that only areas separated by high angle grain boundaries with misorientations above $15^{\circ}$ were considered as grains [17]. The average grain size was calculated as an area fraction.

Measurement of the thermal stability revealed that fine-grained microstructure of both investigated alloys is particularly stable up to the ECAP processing temperature, i.e. $180{ }^{\circ} \mathrm{C}$ [14]. This behaviour was already observed in other $\mathrm{Mg}$ alloys processed similarly [18]. The increased region of stability observed in the LAE442 alloy up to $220^{\circ} \mathrm{C}$ could be associated with the presence of $\mathrm{Al}$ particles and their postponed dissolution, as shown in Ref. [16]. Further evolution of the average grain size with increasing temperature showed a continuous coarsening of the microstructure in both alloys; however, a comparable grain size was observed in samples annealed at $240{ }^{\circ} \mathrm{C}$. Moreover, heterogeneous growth was observed in both alloys resulting in bimodal grain size distribution, see Figs. $2 b$ and $2 c$. Such a microstructure was recently reported as a favorable one for the superplastic behaviour [19].

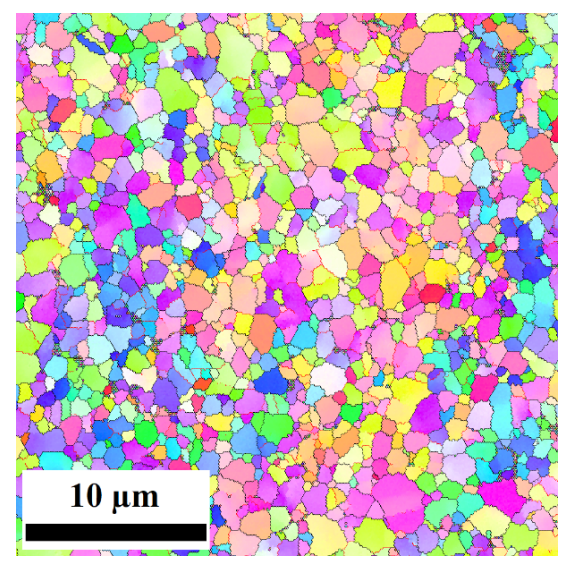

a

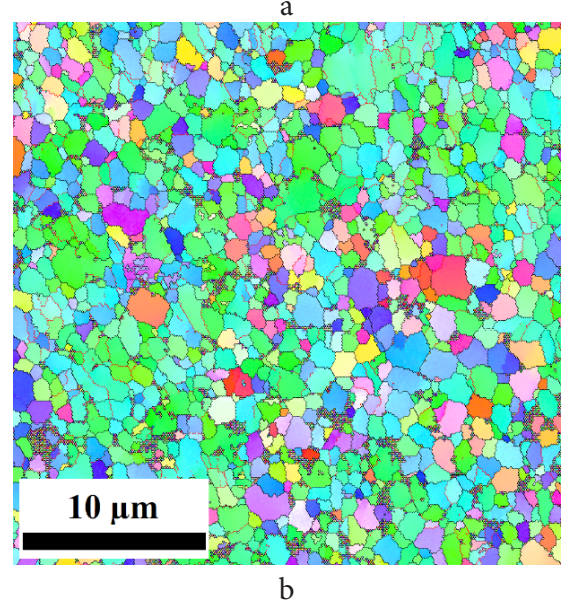

Fig. 1. (Color online) EBSD micrograph of the ECAP processed alloys: AE42 (a) and LAE442 (b).
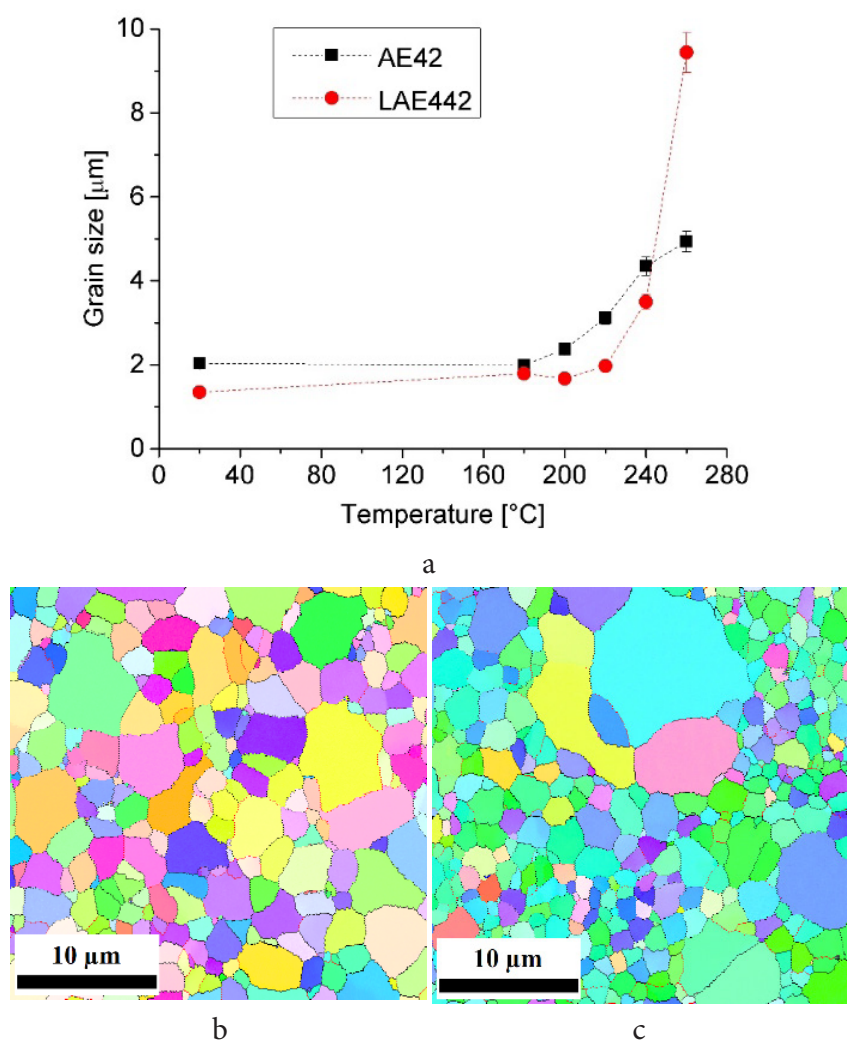

Fig. 2. (Color online) Evolution of the average grain size as a function of annealing temperature (a). EBSD micrographs of the investigated alloys annealed at $240^{\circ} \mathrm{C}$ : AE42 (b) and LAE442 (c). 


\subsection{Strain rate sensitivity parameter}

Investigation of the $m$-parameter was performed at the same set of temperatures as were selected for the thermal stability. Nevertheless, the last temperature of $260{ }^{\circ} \mathrm{C}$ was excluded due to a rapid grain growth observed in the LAE442 alloy. For each temperature, the true strain rate was increased in a step-wise manner from $5 \times 10^{-5} \mathrm{~s}^{-1}$ to $2 \times 10^{-3} \mathrm{~s}^{-1}$. Maximum true stress achieved at each strain rate was recorded after reaching stable flow and the corresponding value of $m$-parameter was calculated in compliance with (1):

$$
m=\frac{\delta \ln (\sigma)}{\delta \ln (\dot{\varepsilon})},
$$

where $\sigma$ is a true strain and $\dot{\varepsilon}$ is strain rate. The results for the limiting temperatures are shown in Fig. 3.

The LAE442 alloy exhibited higher values of $m$-parameter in the whole strain rate range comparing to the AE42 alloy. Interestingly, an increase of the temperature led to a systematic increase of the $m$-parameter in case of the LAE442 alloy, while a systematic decrease was observed for the AE42 alloy. The highest values of $m$-parameter were exhibited by the LAE442 alloy tested at $240^{\circ} \mathrm{C}$. Surprisingly, although the highest value was measured at the strain rate of $10^{-4} \mathrm{~s}^{-1}, m>0.5$ was measured in a whole range of strain rates indicating enhanced superplasticity in the latter case. Moreover, the highest value of $m$-parameter was observed for the strain rate of $10^{-4} \mathrm{~s}^{-1}$ in all measured samples. Consequently, this strain rate was selected for the subsequent deformation tests. The second selected strain rate was $10^{-3} \mathrm{~s}^{-1}$ because LAE442 alloy measured at all temperature conditions exhibited values of $m$-parameter well above 0.3 ; moreover, as mentioned above, the sample measured at $240^{\circ} \mathrm{C}$ had $m>0.5$. Regarding the AE42 alloy, this strain rate was at the limit of possible superplastic behaviour. AE42 tested at $180^{\circ} \mathrm{C}$ had $m \approx 0.3$, but an increase in the temperature to $240{ }^{\circ} \mathrm{C}$ led to a decrease of the $m$-parameter down to 0.2 . Contrary to this fact, AE42 sample was measured also in these conditions for comparison purposes.

\subsection{Tensile tests}

The tensile tests at the aforementioned conditions were performed in order to reveal the possible superplastic behaviour of the fine-grained AE42 and LAE442 alloys. The tests were performed with the special strain rate control, which allows continuous measurement of the $m$-parameter through the whole plastic deformation. Two strain rates were selected in the vicinity of the chosen medium one and were periodically switched as described in detail in Ref. [20]. Note, that the true strain rates were kept constant; therefore, the cross-bar speed was exponentially increased during the experiment. The resulting true strain - true stress curves are shown in Fig. 4 and the calculated evolution of $m$-parameter is shown in Fig. 5 for each condition.

After each tensile test, the fractured sample was removed quickly from the deformation device and water-quenched. Samples from two spots were afterwards cut, specifically one from the uniformly deformed area and one from the nondeformed area in the head. Finally, EBSD investigation was performed in these samples in order to reveal the evolution

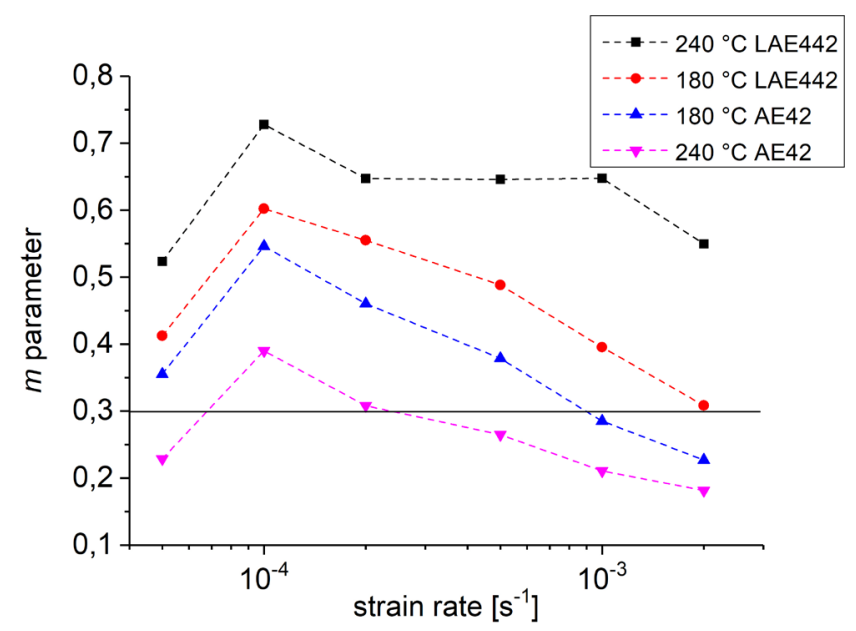

Fig. 3. (Color online) Evolution of $m$-parameter as a function of strain rate.

of the microstructure during the deformation. The resulting values of the average grain size for the conditions having the highest and lowest elongations are shown in Table 1.

Fig. 4 clearly shows that much higher elongations were achieved in the LAE442 alloy regardless of testing parameters. Comparable maximum values of the true strain of about $1.5(350 \%)$ were achieved in three testing conditions out of four ones. The only exception was a combination of higher strain rate and higher temperature, in which true strain of $1.2(230 \%)$ was achieved. On the other hand, the maximum value of the true strain achieved in the AE42 alloy was in sample deformed at $240{ }^{\circ} \mathrm{C}$ and strain rate of $10^{-4} \mathrm{~s}^{-1}$. The observed decrease in elongation from $1.3(270 \%)$ to $1.2(230 \%)$ resulted from a decrease of the temperature to $180^{\circ} \mathrm{C}$. Further decrease of elongation was related to an increase of the strain rate to $10^{-3} \mathrm{~s}^{-1}$ and, similarly as in the LAE442 alloy, the lowest value of true strain was measured for sample deformed at $240^{\circ} \mathrm{C}$ and strain rate of $10^{-3} \mathrm{~s}^{-1}$.

The achieved deformation was closely connected with the evolution of $m$-parameter. There was a systematic difference between the AE42 alloy and LAE442 alloy. A rapid decrease of $m$-parameter below the threshold of 0.3 was observed in all AE42 samples, while in case of the LAE442 alloy, the values of $m$-parameter continuously decreased and reached the level of 0.3 only close to the end of the test. The decrease of $m$-parameter in both alloys could be associated with the recovery and grain growth during the exposure of fine-grained microstructure to elevated temperatures. As shown in Table 1, grain growth in the AE42 alloy was more pronounced regardless of the comparable result of thermal stability measurement, particularly at $180^{\circ} \mathrm{C}$.

Interestingly, average grain size measured in the nondeformed region and in the area of uniformly deformed material was comparable in almost all tested samples. Therefore, grain growth in the individual samples is driven primarily by the temperature exposure and it is not significantly accelerated by the deformation itself. This holds for all samples except the AE42 deformed at $180{ }^{\circ} \mathrm{C}$ and strain rate of $10^{-3} \mathrm{~s}^{-1}$. For this sample, higher average grain size was measured in the non-deformed region, pointing out that dynamic recrystallization could have occurred at some 


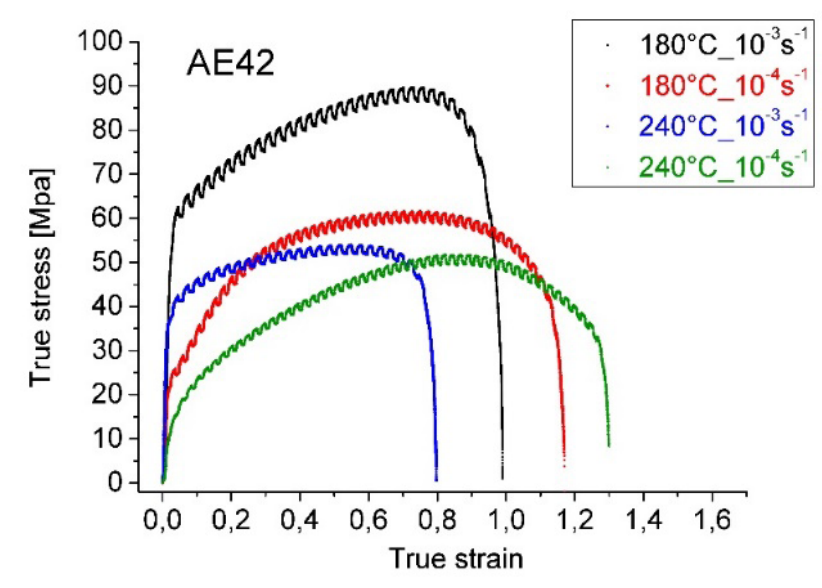

a

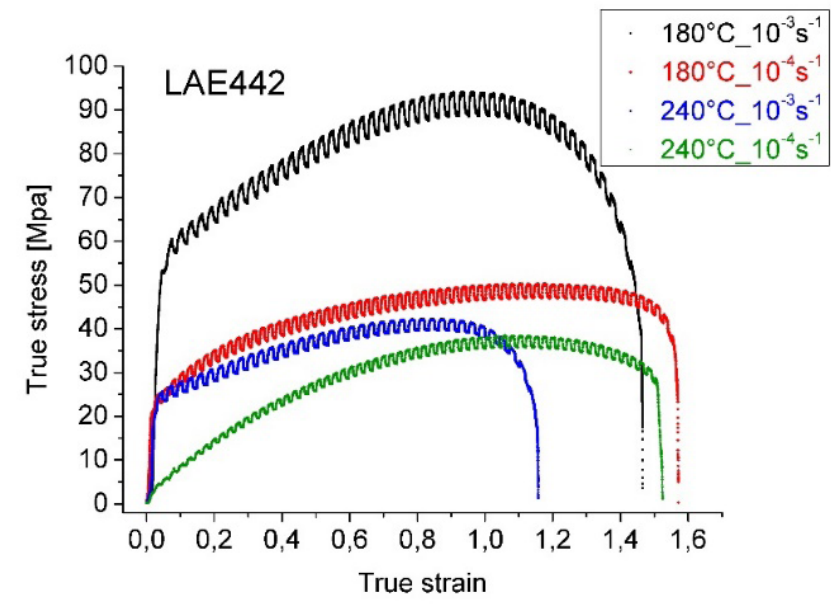

$\mathrm{b}$

Fig. 4. (Color online) True stress-true strain curves for AE42 (a) and LAE442 (b) alloy tested at selected conditions.

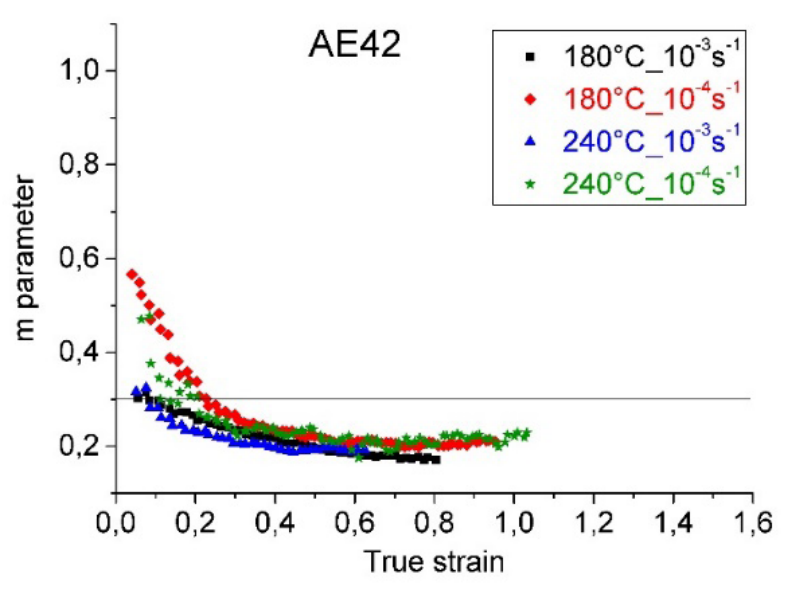

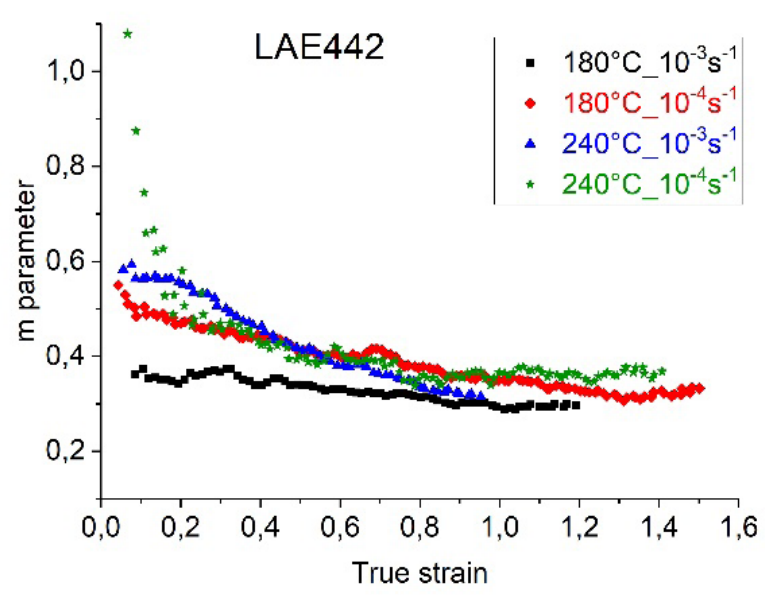

b

Fig. 5. (Color online) Evolution of $m$-parameter calculated from the deformation curves shown in Fig. 4.

Table 1. Average grain size after tensile tests in the areas of interest.

\begin{tabular}{|c|c|c|c|c|}
\hline \multirow{3}{*}{$\begin{array}{l}\text { part of sample / } \\
\text { conditions }\end{array}$} & \multicolumn{4}{|c|}{ grain size, $\mu \mathrm{m}$} \\
\hline & \multicolumn{2}{|c|}{$180^{\circ} \mathrm{C}, 10^{-4} \mathrm{~s}^{-1}$} & \multicolumn{2}{|c|}{$240^{\circ} \mathrm{C}, 10^{-3} \mathrm{~s}^{-1}$} \\
\hline & AE42 & LAE442 & AE42 & LAE442 \\
\hline non-deformed & $5.6 \pm 0.3$ & $2.9 \pm 0.1$ & $5.6 \pm 0.3$ & $4.3 \pm 0.2$ \\
\hline uniformly deformed & $4.7 \pm 0.2$ & $3.3 \pm 0,2$ & $5.3 \pm 0.3$ & $4.3 \pm 0.2$ \\
\hline
\end{tabular}

degree. The grain growth observed in all samples is consistent with the limited thermal stability, as shown in Fig. 2. Highly negative effect of grain growth during the deformation on the achievable elongation is more visible by comparison of two of the main columns in Table 1 . In the AE42 alloy, an increase of the processing temperature from 180 to $240{ }^{\circ} \mathrm{C}$ led to the same amount of grain growth, while in case of the LAE442 alloy to much higher. Nevertheless, the grain growth was more intensive (shorter deformation time), resulting in much lower elongation in both alloys when the strain rate of $10^{-3} \mathrm{~s}^{-1}$ was applied. On the other hand, grain growth had not such detrimental effect on the elongation for strain rate of $10^{-4} \mathrm{~s}^{-1}$ and consequently, the highest values of $m$-parameter were measured in the last stage of deformation of both alloys.
Besides the higher thermal stability, the other source of less steep decrease of $m$-parameter in the LAE42 alloy could be the presence of lithium itself. Lithium dissolved in the Mg-matrix promotes the activation of non-basal slip systems and increases the diffusivity especially along grain boundaries; and therefore, accommodation of grain boundary sliding is more effective $[11,13]$. However, more deformation tests need to be performed in order to properly explore the effect of lithium on the superplastic behaviour of the LAE442 alloy. This need is especially emphasized due to the fact that the evolution of $m$-parameter during the deformation can be significantly different from the first estimation by thermal stability and step-wise tests. 


\section{Conclusion}

In this paper, the possible superplastic behaviour of finegrained magnesium alloys AE42 and LAE442 have been investigated and the first results of this research have been shown. The following conclusions may be drawn:

- The results of studies on the thermal stability and dependence of $m$-parameter on strain rate and temperature indicate the possible superplastic behaviour of both alloys.

- The LAE442 alloy shows significantly higher elongations at the same deformation conditions comparing to the AE42 alloy.

- The highest values of $m$-parameter in the last stage of deformation were measured at the temperature of $240{ }^{\circ} \mathrm{C}$ and strain rate of $10^{-4} \mathrm{~s}^{-1}$, regardless much higher grain growth comparing to deformation at $180{ }^{\circ} \mathrm{C}$. Consequently, deformation of about $1.5(350 \%)$ and $1.3(270 \%)$ was measured for LAE442 and AE42 alloy, respectively.

- Higher values of $\mathrm{m}$-parameter during the deformation and consequently higher elongation observed in LAE442 alloy was attributed to a combination of higher thermal stability and the positive effect of lithium on the activation of non-basal slip systems and diffusion.

Acknowledgements. This work was financially supported by the Czech Science Foundation under the project 14-36566G. B. H. acknowledges the financial support from ERDF and Slovak State Budged by the project ITMS 313011D011 and by Scientific grant agency of the Slovak Republic, project No. VEGA 1/0045/17.

\section{References}

1. P. Minárik, E. Jablonská, R. Král, J. Lipov, T. Ruml, C. Blawert, B. Hadzima, F. Chmelík. Mater. Sci.Eng. C. 73, 736 (2017).
2. C. Rössig, N. Angrisani, P. Helmecke, S. Besdo, J.-M. Seitz, B. Welke, N. Fedchenko, H. Kock, J. Reifenrath. Acta Biomater. 25, 369 (2015).

3. T. G. Langdon. Acta Mater. 61, 7035 (2013).

4. P. Lukáć, Pokroky Mat. Fyziky Astron. 36, 91 (1991).

5. O. A. Kaibyshev. Superplasticity of Alloys, Intermetallides and Ceramics. Springer, Germany (2011).

6. F. Khan, S. K. Panigrahi. J. Alloys Compd. 747, 71 (2018).

7. Z. Kang, L. Zhou, J. Zhang, Mater. Sci. Eng. A. 633, 59 (2015).

8. S. Kandalam, R. K. Sabat, N. Bibhanshu, G.S. Avadhani, S. Kumar, S. Suwas. Mater. Sci. Eng. A. 687, 85 (2017).

9. B. R. Powell, V. Rezhets, M.P. Balogh, R. A. Waldo. JOM. 54,34 (2002).

10. F. R. Cao, H. Ding, Y.L. Li, G. Zhou, J.Z. Cui. Mater. Sci. Eng. A. 527, 2335 (2010).

11. K. Edalati, T. Masuda, M. Arita, M. Furui, X. Sauvage, Z. Horita, R.Z. Valiev. Sci. Rep. 7, 2662 (2017).

12. H. Matsunoshita, K. Edalati, M. Furui, Z. Horita, Mater. Sci. Eng. A. 640, 443 (2015).

13. Y. Yoshida, L. Cisar, S. Kamado, Y. Kojima, Mater. Trans. 43, 2419 (2002).

14. P. Minárik, R. Král, J. Čížek, F. Chmelík. Acta Mater. 107, 83 (2016).

15. P. Minárik, R. Král, M. Janeček. Appl. Surf. Sci. 281, 44 (2013).

16. P. Minárik, J. Čížek, J. Veselý, P. Hruška, B. Hadzima, R. Král. Mater. Charact. 127, 248 (2017).

17. P. Lejcek. Grain Boundary Segregation in Metals. Springer Science \& Business Media (2010).

18. M. Janeček, T. Krajňák, P. Minárik, J. Čížek, J. Stráská, J. Stráský. IOP Conf.Ser. Mater. Sci. Eng. 194, 012052 (2017).

19. R. Lapovok, Y. Estrin, M.V. Popov, T.G. Langdon. Adv. Eng. Mater. 10, 429 (2008).

20. J. Stráská, J. Stráský, P. Minárik, M. Janeček, B. Hadzima. Mater. Sci. Eng. A. 684, 110 (2017). 